www.jmscr.igmpublication.org

Impact Factor 5.84

Index Copernicus Value: 83.27

ISSN (e)-2347-176x ISSN (p) 2455-0450

crossref DOI: _https://dx.doi.org/10.18535/jmscr/v5i7.135

Journal Of Medical Science And Clinical Research

IGM Publication

An official Publication of IGM Publication

\title{
Endovascular Treatment of Carotid Cavernous Fistulae: A Study of Management and Outcome
}

\author{
Authors
Dr Bharatkumar Mudalgi ${ }^{1}$, Dr Manohar Kachare ${ }^{2}$, Dr Manish Shrivastava ${ }^{3}$, Dr Akshay Kulkarni ${ }^{4}$
${ }^{1}$ Associate Professor, ${ }^{2}$ Professor and Head, ${ }^{4}$ Senior Resident \\ Department of Radiodiagnosis, Government Medical College, Miraj (MS) India
}

${ }^{3}$ Head of Department of Interventional Neuroradiology, Kokilaben Dhirubhai Ambani Hospital \& Medical

Research Institute.Mumbai (MS) India

Corresponding Author

\section{Dr Bharatkumar Mudalgi}

Associate Professor Department of Radiodiagnosis, Government Medical College, Miraj (MS) India

\begin{abstract}
Background: Carotid cavernous fistulae (CCF's) are spontaneous or acquired communications between the carotid artery and the cavernous sinus and are commonly associated with acute visual loss. The presenting complaints depend upon size, location, duration of fistula and presence or absence of collaterals. These fistulas are classified on the basis of etiology, hemodynamic features, or the angiographic appearance. Various noninvasive modalities used for diagnosis include computed tomography, CT or MR angiography and doppler studies. Cerebral angiography is the gold standard test for carotid cavernous fistulae. Endovascular treatment of these lesions is becoming increasingly popular for definitive management of these fistulae. We undertook this study to determine site and type, vascular approach for effective management and efficiency of endovascular management of carotid-cavernous fistula.
\end{abstract}

Aims and Objective: (1) To determine the efficiency of endovascular management of carotid-cavernous fistula.(2) To determine the site and type of carotid-cavernous fistula by the means of diagnostic conventional/ digital subtraction angiography. (3) To determine the vascular approach for effective management of the fistula (4) complete cure of the carotid-cavernous fistula.

Materials and Methods: This was a prospective cohort study consisting of 60 patients diagnosed with carotid cavernous fistula. The clinical presentation was established for each patient. Clinical symptoms, signs were noted down. All patients underwent a diagnostic angiography. Angiographic findings were noted with a special emphasis on location, type, relation of fistula to carotid and presence of collaterals. All patients underwent a diagnostic angiogram prior to treatment. Endovascular treatment was done according to standard protocol. Mostly balloon occlusion of the fistula site with or without coil embolisation was done in direct type of fistula. Post procedure patient was observed for symptomatic response and thus accomplishment of pre-therapeutic goals. Outcomes of the procedure were graded as. (1) Complete cure. (2) Improvement but with residual pathology. (3) Procedure abandoned. (4) Complications. The follow-up protocol included clinical examination at 1-3 month's interval and the following year.

Results: The analyses of demographic data revealed that out of 60 patients 41 (68.33\%) were males and 19 (31.66\%) were females with a M: F ratio being 1:0.46. The youngest and oldest patient was 6 yrs and 68 yrs old respectively with a mean age 37 years. Direct fistula was more common in males (37/41) while indirect fistula (12/19) was found to be more common in females. Traumatic Fistulas were more common in males (36/41) while spontaneous fistulas were more common in females (15/19). The common symptoms associated with CCF's were 
Proptosis (96\%), redness of eyes (75\%) and diplopia (33\%). Least common symptoms were diminished vision (23\%) and pain $(11 \%)$. Common signs were conjunctival injection and restricted extra ocular muscular movements which were seen in $75 \%$ patients each. Frequency of venous drainage pattern in patients revealed that most common drainage was through ipsilateral superior opthalmic vein. Endovascular treatment was done in 2 sessions in majority of the cases (27/60) while only 1 patient needed more than 5 sessions. Most of the patients (75\%) were treated by trans arterial route while 7 patients (11.66\%) was treated by transvenous route while 8 patients (13.33\%) were treated using transarterial as well as transvenous route. Most common embolisation material used was balloons and coils. Glue and PVA was used in 4 and 1 patients respectively. The results of endovascular treatment were found to be excellent with $42 / 60$ (70\%) patients getting completely cured. There was improvement in symptoms but with residual pathology in 12/60 (20\%) patients while complications occurred and procedure was abandoned in 2 patients each. Spontaneous closure of fistula was seen in 2 patients.

Conclusion: Endovascular management of Carotid cavernous fistulae (CCF's) is becoming increasingly popular. In acute setting this can be a life saving procedure. Complete cure either angiographic or symptomatic is significant following a proper plan and use of appropriate therapy in least probable sessions.

Keywords: Carotid cavernous fistulae, Angiography, Endovascular treatment, Outcome.

\section{Introduction}

Continuous development of neuroradiology and interventional neuroradiology has especially revolutionnized the diagnostic and therapeutic management of the intracranial vascular pathologies ${ }^{[1]}$. It has opened new horizons in fullvalue diagnosis and endovascular treatment of the diseases and injuries of arteries, veins and sinuses of the brain and dura mater ${ }^{[2]}$. Today a combination of direct neurosurgical and intravascular interventions or most of the times the latter has become standard in rendering medical care to patients with this life-threatening pathology. Arteriovenous malformations of the dura mater make $10-15 \%$ of all intracranial pathology ${ }^{[3]}$. The majority of them develop spontaneously against a background of transformations of a vascular wall caused by age, hormonal changes, trauma or thrombosis of large vessels. The first placed among them is occupied by carotid cavernous fistula, which however has trauma as the most common etiology ${ }^{[4]}$.

Carotid cavernous fistulae (CCF's) are spontaneous or acquired communications between the carotid artery and the cavernous sinus. These lesions may be associated with acute visual decline or hemorrhage ${ }^{[5]}$. Hence an effective endovascular intervention is performed in medical centers in which interventional neuroradiologists, neurosurgeons and neurophysicians have developed a co-operative team effort to offer the best array of treatment services for these patients. With minimal invasive therapeutic procedures becoming increasingly popular, the intervenetional radiologist is poised to play a pivotal role [6]. Sub selective catheterization and angiography of the cranial vasculature related to this pathology has helped us in an intense angiographic search for the supply to the fistula. Hamby ${ }^{[7]}$ states, "Its management should be attacked as in other fistulas of the body rather than attempting piecemeal progressive expansion of the feeding arteries."

The cavernous venous sinus or the venous proper are of special interest from the anatomicphysiologic point of view. The internal carotid artery with periarterial nervous plexuses, surrounding it, goes inside the sinus cavity ${ }^{[8]}$. The sinus walls contain the III, IV, V (the 1st and 2nd branches) and VI pairs of cranial nerves. Hypophysis and external walls of the sphenoid sinus are adjacent to the inner wall of the cavernous sinus. Thus, it differs greatly from other venous sinuses due to its localization and structure [9]. The relationship between the venous sinus proper and ICA is of peculiar importance. The venous sinus proper cannot change a lumen width as a dense cavernous capsule limits it. Thus, pulse increase of the ICA volume is possible only at the expense of reduction of the cavernous sinus volume. The cavernous sinus is the most important regulator of cerebral circulation. This "venous heart" has a great impact on intracranial venous circulation. Exclusion of the intra-sinusal part of ICA results in ceasing pulsation of venous 
blood inside the sinus and deceleration of venous circulation in the skull cavity ${ }^{[10]}$.

\section{Aims and Objective}

1. To determine the efficiency of endovascular management of carotidcavernous fistula.

2. To determine the site and type of carotidcavernous fistula by the means of diagnostic conventional/digital subtraction angiography.

3. To determine the vascular approach for effective management of the fistula.

4. Complete cure of the carotid-cavernous fistula.

\section{Materials and Methods}

This was a prospective cohort study consisting of 60 patients diagnosed with carotid cavernous fistula. The clinical presentation, symptoms and signs were noted down. All patients underwent a diagnostic angiography. Angiographic findings were noted with a special emphasis on location, type, relation of fistula to carotid and presence of collaterals. All the details were noted into a prepared proforma. Most of the patients were diagnosed clinically supplemented by imaging. Traumas being most common etiology, CT/ MRI Brain were used to diagnose the lesion along with other associated head injuries, which would need treatment on priority. Rest musculoskeletal injuries were also evaluated and treated on priority. These lesions also provided a base line for further follow up. All patients underwent a diagnostic angiogram prior to treatment. Detailed informed consent was taken from all the patients. Patient underwent anesthesia fitness and admission a day before the procedure. At the onset of the procedure, 5 -French sheath (Avanti, Cordis, Johnson and Johnson) was introduced in the common femoral artery in the groin. The common carotids as well as its branches, the EGA and the ICA were selectively catheterized with Head Hunter catheter, (cordis, Johnson and Johnson) and 0.035 Terumo glide wire was used where indicated. All contrast injections were performed using the pressure injector with 4-7c.c of nonionic contrast for the selective studies. The line of management was decided upon after taking into consideration the feasibility of endovascular approach. The hardware and the embolisation or occlusion materials were dependent on the goal of the procedure, the selectivity accomplished. Mostly balloon occlusion of the fistula site with or without coil embolisation was done in direct type of fistula. Non-absorbable liquid, n-butyl cyanoacrylate glue was used in dural type of fistulous site were decided depending on the feasibility of approach and angiographic road maps to the fistula. Post procedure patient was observed for symptomatic response and thus accomplishment of pre-therapeutic goals. Outcomes of the procedure were graded as

1. Complete cure.

2. Improvement but with residual pathology.

3. Procedure abandoned.

4. Complications.

The follow- up protocol included clinical examination at 1-3 month's interval and the following year. Clinical photographs were obtained of each patient, before initiation of treatment, and at the end of each session and during every follow up evaluation. Conventional radiograph were also obtained to see position of balloon or coils used. Repeat angiography was done in patient who showed non-satisfying response and next strategies were planned accordingly.

\section{Results}

60 patients diagnosed with carotid cavernous fistula were included in our study. Endovascular management was attempted in all the patients but in 2 cases the procedure had to be abandoned due to technical difficulties. In all the patients analysis of personal and demographic data revealed that out of 60 patients $41(68.33 \%)$ were males and 19 $(31.66 \%)$ were females with a M:F ratio being 1:0.46 (Figure 1). 


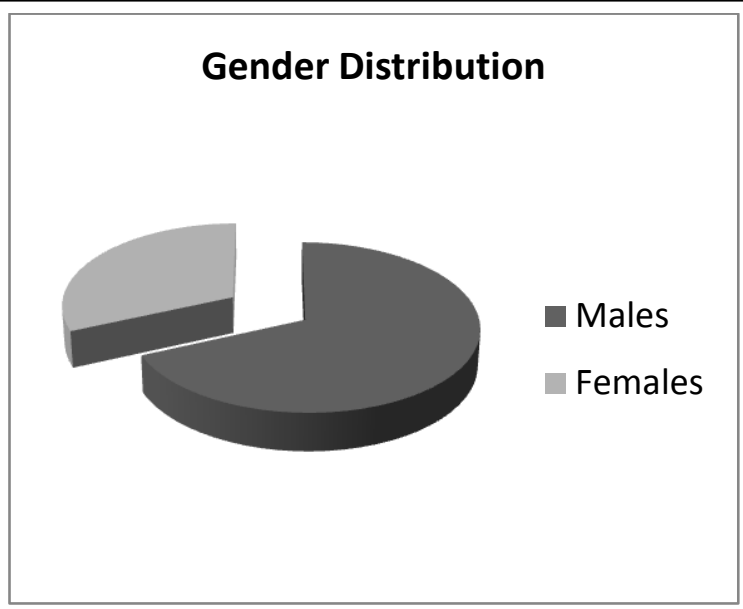

Figure 1: Gender Distribution of the studied cases.

Age distribution of the studied cases showed that the most common age group to which patient belonged was 20-40 years followed by $40-60$ years and 0-20 years. Carotid cavernous fistula was least common in patients above the age of 60 years (Figure 2).

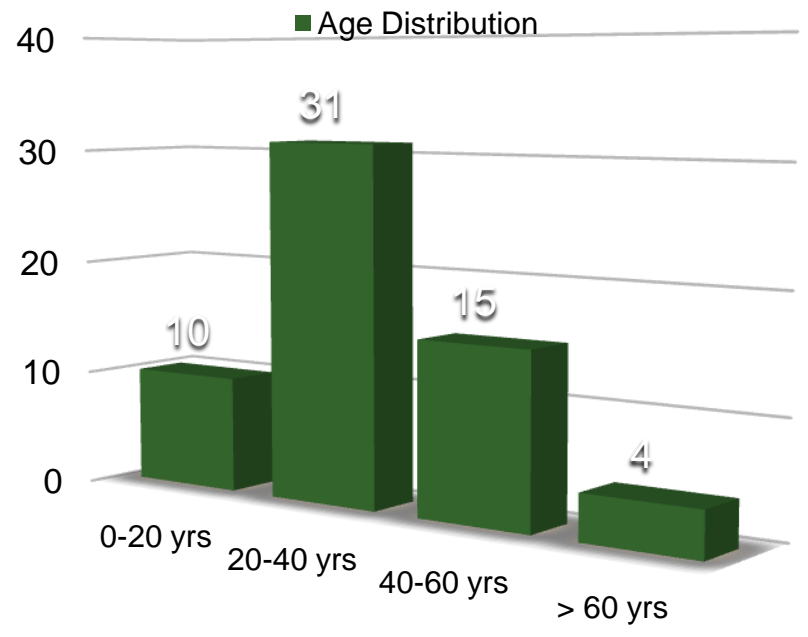

Figure 2: Age distribution of the studied cases.

The patients were divided according to angiographic classification as direct and indirect types. Direct CCF was more common in males and was seen in $37 / 41$ patients $(90.24 \%)$ while indirect fistula was more common in females and which was seen in 12/19 patients (Table 1)

Table 1: Type of carotid cavernous fistula in studied cases.

\begin{tabular}{|l|c|c|}
\hline Type & Males & Females \\
\hline Direct & 37 & 7 \\
\hline Indirect & 4 & 12 \\
\hline Total & 41 & 19 \\
\hline
\end{tabular}

The analysis of spontaneous and traumatic CCF revealed that overall most common type of fistula was traumatic which was seen in $40 / 60$ patients (66.67\%). Traumatic fistula was more common in males and was seen in 36/41males while spontaneous fistula was more common in females and was seen in 15/19 females (Figure 3).

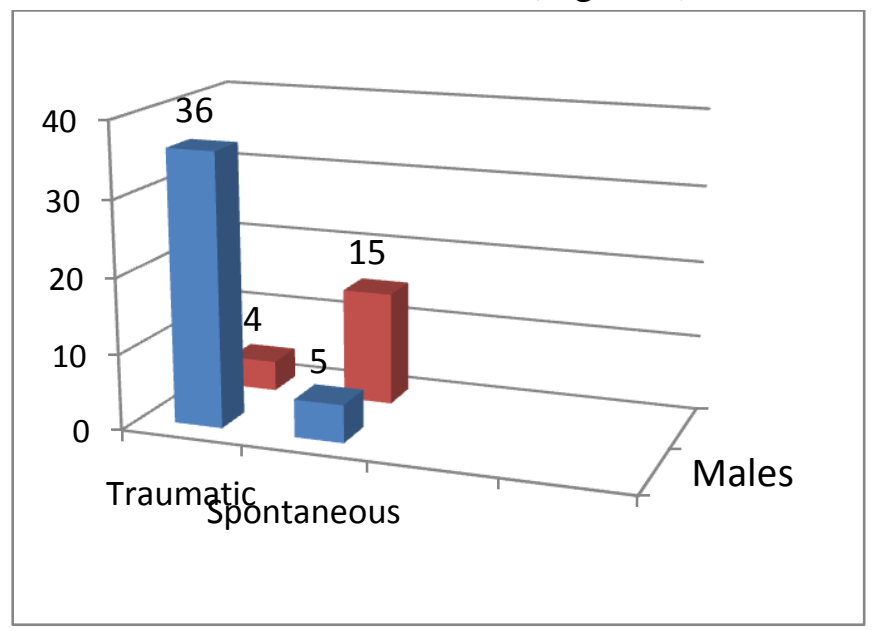

Figure 3: Traumatic and Spontaneous carotid cavernous fistula in studied cases.

The analysis of signs and symptoms of the patients revealed that the common symptoms associated with CCF's were Proptosis (96\%), redness of eyes (75\%) and diplopia (33\%). Least common symptoms were diminished vision $(23 \%)$ and pain $(11 \%)$. Common signs were conjunctival injection and restricted extra ocular muscular movements which were seen in $75 \%$ patients each followed by thrill which was seen in $70 \%$ cases (Table 2).

Table 2: Signs and symptoms in studied cases

\begin{tabular}{|lcc|}
\hline Symptoms & $\begin{array}{c}\text { No of } \\
\text { patients }\end{array}$ & Percentage \\
\hline Proptosis & 58 & 96 \\
\hline Red Eye & 45 & 75 \\
\hline Diplopia & 33 & 55 \\
\hline Headache & 19 & 33 \\
\hline Diminished Vision & 15 & 23 \\
\hline Pain & 7 & 11 \\
\hline Signs & 45 & 75 \\
\hline $\begin{array}{l}\text { Conjunctival } \\
\text { Congestion }\end{array}$ & 45 & 75 \\
\hline $\begin{array}{l}\text { Restricted External } \\
\text { Ocular movements }\end{array}$ & 42 & 70 \\
\hline Thrill & 15 & 23 \\
\hline Diminished vision & & \\
\hline
\end{tabular}




\section{JMSCR Vol||05||Issue||07||Page 25128-25137||July}

The analysis of distribution of the patients according to site of direct fistula on cavernous ICA revealed that it was most commonly found at C5 which was seen in 23/44 patients. The details are summarized in the table given below (Table 3)

Table 3: Site of direct fistula in studied cases

\begin{tabular}{|l|c|c|c|}
\hline $\mathbf{C}_{\mathbf{1}}$ & $\mathbf{2}$ & $\mathbf{C}_{\mathbf{1}}-\mathbf{C}_{\mathbf{2}}$ & $\mathbf{1}$ \\
\hline $\mathbf{C}_{\mathbf{2}}$ & 0 & $\mathrm{C}_{2}-\mathrm{C}_{3}$ & 2 \\
\hline $\mathbf{C}_{\mathbf{3}}$ & 5 & $\mathrm{C}_{3}-\mathrm{C}_{4}$ & 5 \\
\hline $\mathbf{C}_{\mathbf{4}}$ & 4 & $\mathrm{C}_{4}-\mathbf{C}_{5}$ & 2 \\
\hline $\mathbf{C}_{\mathbf{5}}$ & 23 & & \\
\hline
\end{tabular}

The analysis of the pattern of angiographic presentation in dural fistula revealed following findings (Table 4).

Table 4: Angiographic presentation in dural fistula in studied cases

\begin{tabular}{|c|c|c|c|c|c|c|c|c|}
\hline \multirow[t]{2}{*}{ CASE } & \multicolumn{3}{|c|}{ ARTERIAL SUPPLY } & \multicolumn{5}{|c|}{ VENOUS DRAINAGE } \\
\hline & ICA & $\begin{array}{c}\text { MMA/A } \\
\text { MA }\end{array}$ & ASA & IMA & SOV & IOV & IPS & OPP \\
\hline $\mathbf{1}$ & ILT & $+/+$ & - & + & - & + & - & - \\
\hline 2 & ILT & $+/+$ & - & - & + & - & - & - \\
\hline 3 & ILT & $+/+$ & - & + & + & - & - & - \\
\hline 4 & ILT & - & + & + & + & - & - & - \\
\hline 5 & $\begin{array}{l}\mathrm{B} / \mathrm{L} \\
\text { ILT }\end{array}$ & $+/+$ & & + & + & & & \\
\hline 6 & ILT & $-/-$ & - & - & + & - & - & - \\
\hline 7 & ILT & $+/-$ & - & + & + & - & - & - \\
\hline 8 & ILT & $-/-$ & - & - & + & + & - & - \\
\hline 9 & $\begin{array}{l}\mathrm{B} / \mathrm{L} \\
\mathrm{ILT}\end{array}$ & $+/-$ & & & + & & & - \\
\hline 10 & $\begin{array}{l}\mathrm{B} / \mathrm{L} \\
\mathrm{ILT}\end{array}$ & $\begin{array}{l}\text { B/LMM } \\
\mathrm{A}\end{array}$ & & & + & & & - \\
\hline 11. & ILT & MMA & " & $"$ & + & - & + & - \\
\hline 12. & $\begin{array}{l}\text { ILT } \\
\text { MHA }\end{array}$ & MMA & & & + & & & + \\
\hline
\end{tabular}

Frequency of venous drainage patterns were studied in all the cases. The most common venous drainage was found to be in ipsilateral superior ophthalmic vein followed by ipsilateral inferior petrosal sinus and ipsilateral inferior ophthalmic vein. The findings of this pattern are summarized in table below. No venous drainage was found in contra-lateral superior petrosal sinus and contralateral cortical veins (Table 5).
Figure 4 - selective left internal carotid artery angiogram frontal view (Left) and Lateral View (Right) a large carotico-cavernous fistula with prominent superior ophthalmic and sphenoparietal veins

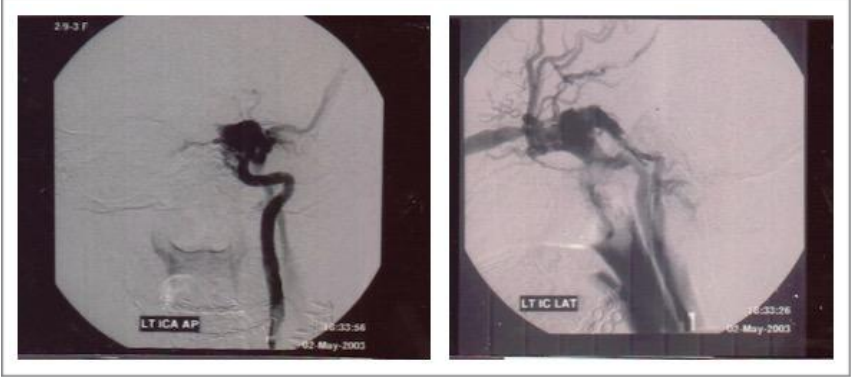

Figure 5 - selective left internal carotid artery angiogram frontal view (Left)and lateral view (Right) post balloon embolisationstatus shows total obliteration of fistula and draining veins.
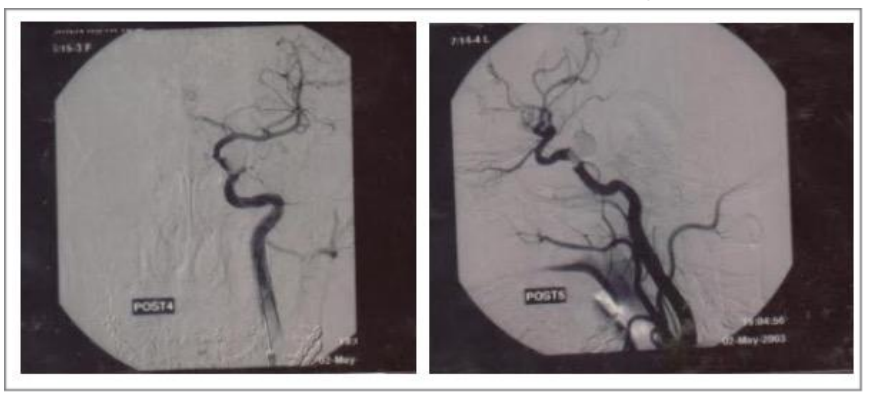

Figure 6 - selective left internal carotid artery angiogram frontal view (Left) and lateral view (Right) shows a large carotico-cavernous fistula with prominent superior ophthalmic vein.



Figure 7- selective left internal carotid artery angiogram frontal view (Left) and lateral view (Right )post coil embolisationstatus shows total obliteration of fistula and draining veins.
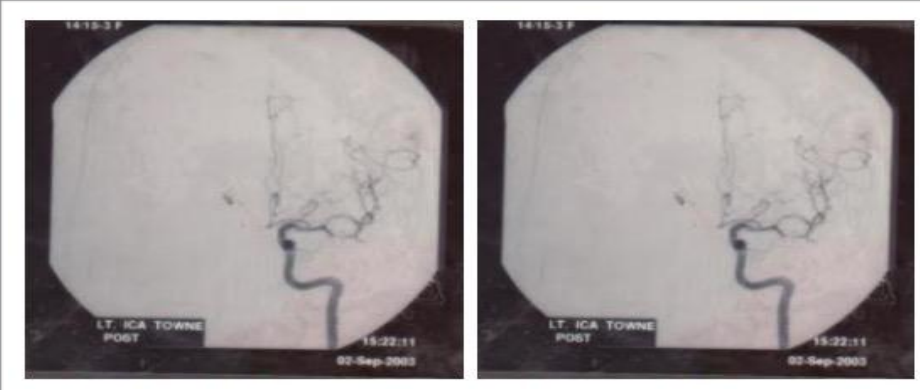
Table 5: venous drainage patterns in studied cases

\begin{tabular}{|lcc|}
\hline VENOUS DRAINAGE & Ipsilateral & Contralateral \\
\hline Superior ophthalmic vein & 58 & 9 \\
\hline Inferior petrosal sinus & 33 & 3 \\
\hline Interior ophthalmic vein & 29 & 1 \\
\hline Facial vein & 20 & 5 \\
\hline Pteyrigoid plexus & 12 & 1 \\
\hline Superior petrosal sinus & 12 & 0 \\
\hline Opposite cav. Sinus & - & 16 \\
\hline Cortical veins & 10 & 0 \\
\hline
\end{tabular}

The most common approach used for endovascular treatment was transarterial. While transvenous and both transarterial and transvenous approach was used in minority of patients i.e. 7 and 8 patients respectively (Figure 4).

Figure 8: Endovascular approach for treatment in studied cases.



Various materials which were used for endovascular management of CCFs included balloons, coils, Glue and PVA. In some cases both balloon and coils had to use in same patient (Table 6).

Table 6: Materials used for embolisation

\begin{tabular}{|lcc|} 
Endovascular treatment & $\begin{array}{c}\text { No Of } \\
\text { patients }\end{array}$ & Percentage \\
\hline Balloons & 19 & $31.67 \%$ \\
\hline Coils & 13 & $21.67 \%$ \\
\hline Both balloons Coils & 20 & $33.33 \%$ \\
\hline Glue & 4 & $6.67 \%$ \\
\hline PVA & 1 & $1.67 \%$ \\
\hline
\end{tabular}

Figure 9- Plain frontal and lateral radiographs 24 hours after procedure showing position of the balloon (Above) and coils (Below).

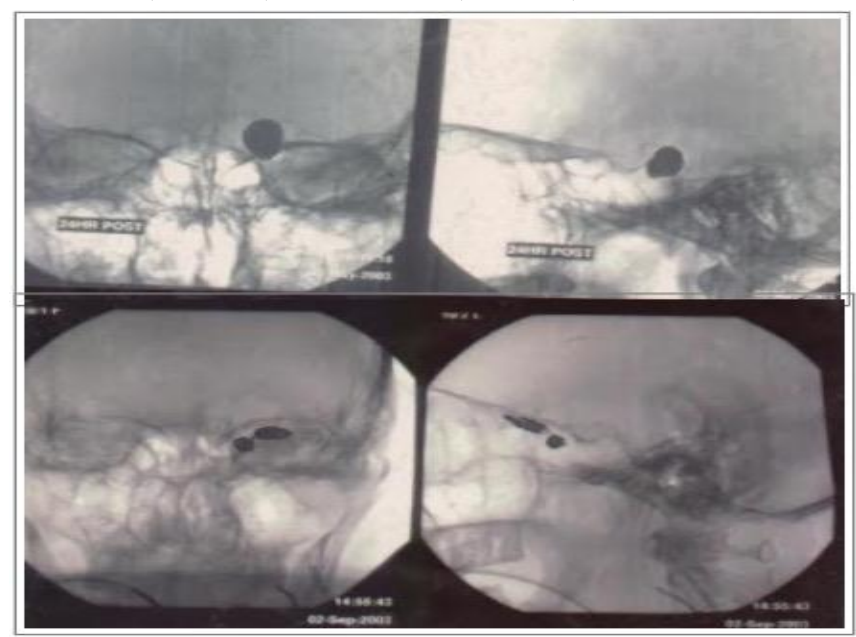

Figure 10:- selective right internal carotid artery angiogram frontal view (Left) and Lateral view (Right) showing a large carotico-cavernous fistula with prominent spheno-parietal vein and internal jugular vein.

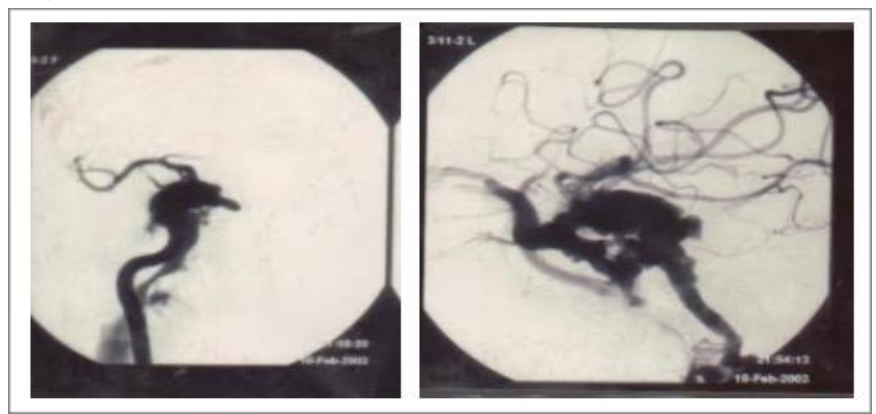

Figure 11: selective right internal carotid artery angiogram frontal view (Left)and lateral view (Right) post balloon embolisationstatus shows total obliteration of fistula and draining veins.

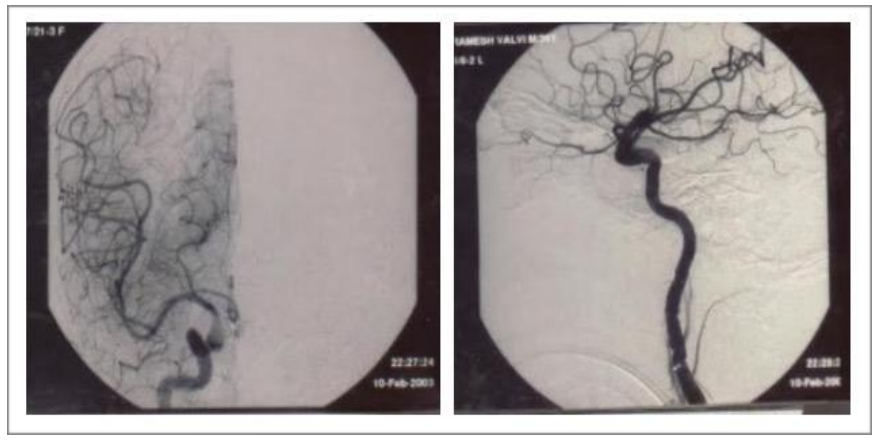

The sessions required for the patient for satisfactory management of CCF were studied. Majority of the patients required 2 or 3 sessions. While only 1 session was required in 2 patients and more than 5 sessions were required in only 1 patient (table 7). 
Table 7: Sessions required for the treatment in studied cases.

\begin{tabular}{|c|c|c|}
\hline SESSIONS & No. of Patients & Percentage \\
\hline 1 & 2 & $3.33 \%$ \\
\hline 2 & 27 & $45 \%$ \\
\hline 3 & 19 & $31.67 \%$ \\
\hline 4 & 7 & $11.67 \%$ \\
\hline 5 & 4 & $6.67 \%$ \\
\hline$>5$ & 1 & $1.67 \%$ \\
\hline
\end{tabular}

Finally the outcome of endovascular treatment was studied in treated patients. Majority of the patients i.e. 42/60 (70\%) got cured and had no residual pathology after endovascular treatment (Here complete cure means a total reversion of the disease both clinically and on angiographic analysis.). In $12 / 60$ patients (20\%) there was significant clinical improvement but there was some residual pathology despite multiple sessions of endovascular therapy (Improvement with residual pathology included complete clinical cure but angiography showing small residual fistula with or without associated psuedoaneurysm of which some could be treated with conservative method while some with definitive ones.). Procedure was abandoned in 2/60 patients due to technical difficulties and complications and spontaneous closure of fistula was seen in $2 / 60$ patients each (Table 8).

Table 8: Outcome of the studied cases

\begin{tabular}{|lcc|}
\hline Outcome & Patients & Percentage \\
\hline $\begin{array}{l}\text { Complete cure. } \\
\text { Improvement but with residual } \\
\text { pathology }\end{array}$ & $42 / 60$ & $70 \%$ \\
\hline Procedure abandoned. & $2 / 60$ & $20 \%$ \\
\hline Complications & $2 / 60$ & $3.3 \%$ \\
\hline Spontaneous closure of fistula & $2 / 60$ & $3.3 \%$ \\
\hline
\end{tabular}

\section{Discussion}

In our series of 60 patients 44 patients had direct fistula. Traumatic fistula was seen in 40 patients out of which 35 were males and 5 were females. Spontaneous fistula was seen in 20 patients out of which majority (15) were females. The most common presenting symptoms was proptosis (96\%) and 70\% had pulsating exophthalmos. C5 part of cavernous was the favored site for the rent.
45 patients received treatment out of which 19 patients were completely cured by balloon embolisation only while 13 patients underwent coil embolisation after one or two sessions of balloon embolisation. Procedure was abandoned in 3 patients due to procedure related complications such as dissection of common carotid, common iliac with distal aorta. One of these had a post procedure hemiplegia. The most common indication for ICA occlusion was a sinus which could be entered but could not be occluded. In case of indirect fistula our study included predominantly type D fistulas. Most patients do not have bruit (none of our patients did) or pulsatile exophthalmos (none of our cases), which indicate a vascular lesion. Diagnosing these slow flow fistulas is clinically difficult ${ }^{[11]}$. The symptoms are not as dramatic as in traumatic high flow cavernous sinus fistulas this diagnosis should always be considered in patients with a red eye and arterialized episcleral vessels ${ }^{[12]}$. Several techniques have been used to attempt fistulous occlusion. Carotid compression is a simple maneuver that can be tried ${ }^{[13]}$. In our series Carotid compression alone was not of any great help primarily but can be very effective after partial of failed embolisation.

Endovascular embolization of ECA feeders has a high success rate. In type D fistulas, the ECA system is usually embolized first, since it may be sufficient to decrease symptoms. In bilateral fistulas, embolisation of the most symptomatic side may also occlude the contralateral fistula ${ }^{[14]}$. When there is predominant ICA supply or when ECA embolisation is insufficient, venous embolization is indicated. The purpose of venous embolization is to occlude the fistula without rerouting venous drainage to conical structures. When catheterization is possible, transvenous embolisation has high $(100 \%)$ occlusion rates ${ }^{[15]}$. Some authors report a $50 \%$ rate of catheterization of the inferior petrosal sinus not detected at angiography ${ }^{[16]}$, but in our hands we estimate a $100 \%$ success rate, even in cases in which the inferior petrosal sinus is not seen. Some investigators have described direct exposure of 
superior ophthalmic vein ${ }^{[17,18]}$ and embolisation via SOV. But In our series we don't find it necessary to use this more invasive approach. Embolic materials used for the embolization include coils or balloons for transvenous approach [19]. PVA particles and Glue can be used for transarterial embolisation. The results of both methods used were similar, but we prefer coils because they allow better control as initial measure and then glue for completeness ${ }^{[20]}$. Controversy still exists over the natural history and treatment of dural CCFs, Several authors have reported that many of these patients will have alleviation of symptoms from spontaneous thrombosis with time, and therefore treatment should not be instituted ${ }^{[21]}$ Although dural CCFs tend to be low-flow and low-pressure lesions, as compared with direct CCF's, many patients with serial ophthalmologic examinations who have developed progressive visual deterioration ${ }^{[22]}$. Our current recommendation is that in patients with dural CCFs without rapidly progressive visual deterioration, evidence of abnormal cortical venous drainage, hypoxic ocular changes involving the retina and optic nerve, or ischemic keratopathy, a trial of manual carotid arteryjugular vein compression therapy should be attempted first '"If patients do not respond to this therapy and continue to have symptoms of visual disturbance, headache, diplopia, and chemosis, then embolisation therapy may be warranted ${ }^{[23]}$.

For direct carotid fistulae, a transarterial approach with detachable balloons is usually attempted first. However, if this technique fails, treatment with a variety of newer embolic agents, as well as newer microcatheters and guidewires, has greatly facilitated treatment by the transvenous approach. Indirect CCFs can have a wide spectrum of signs and symptoms. Diminishing visual activity is an ominous finding in these cases. Small degrees of visual loss caused by hypoxic ocular consequences of CCFs are often reversible if rapid definitive treatment in institute ${ }^{[24]}$. However, visual deterioration to the point of complete loss of light perception is often irreversible even if prompt closure of the fistula is achieved. Visual decline can be rapid, with progression total blindness over several hours. All patients should be instructed to observe for changes in visual acuity and to undergo frequent ophthalmologic examinations. Any visual decline is an indication for urgent treatment. Before visual decline is ascribed to the hypoxic vascular changes secondary to the fistula, associated cause of visual function decline such as retinal hemorrhages, papilloedema, glaucoma, cataracts, and corneal edema should be excluded. The goal of embolisation is the alleviation of patient symptoms, not angiographic cure. Subtotal occlusion of dural CCF is often sufficient for clinical improvement, and subsequent angiographic and clinical cure is common particularly with liquid adhesive agents ${ }^{[25]}$.

\section{Conclusions}

1. Interventional neurovascular techniques to treat caroticocavernous fistula of traumatic or spontaneous variety have become accepted forms of therapy. Particularly in the acute setting, these techniques may be lifesaving in preventing uncontrollable hemorrhage. The goal of therapy for fistulae involving the carotid artery should be preservation of vision and carotid artery.

2. High resolution digital subtraction angiography may help in classifying $\mathrm{CCF}$ into dural and direct type and thus formulate a strategy to treat it either by a balloon or coil or both with or without preservation of parent ipsilateral carotid artery.

3. Complete cure either angiographic or sym ptomatic is significant following a proper plan and use of of appropriate therapy in least probable sessions.

\section{Conflict of Interest: None}

\section{References}

1. Mueller OM, Schlamann M, Mueller D, Sandalcioglu IE, Forsting M, Sure U. 
Intracranial aneurysms: optimized diagnostic tools call for thorough interdisciplinary treatment strategies. Therapeutic Advances in Neurological Disorders. 2011;4(5):267-279.

2. Diaz O, Rangel-Castilla L. Endovascular treatment of intracranial aneurysms.Handb Clin Neurol. 2016;136:1303-9

3. Shownkeen H, Yoo K, Leonetti J, Origitano TC. Endovascular Treatment of Transverse-Sigmoid Sinus Dural Arteriovenous Malformations Presenting as Pulsatile Tinnitus. Skull Base. 2001;11(1):13-23.

4. Fattahi TT, Brandt MT, Jenkins WS, Steinberg B. Traumatic carotid-cavernous fistula: pathophysiology and treatment. J Craniofac Surg. 2003 Mar;14(2):240-6.

5. Razeghinejad M-R, Tehrani MJ. Sudden Onset and Blinding Spontaneous Direct Carotid-Cavernous Fistula. Journal of Ophthalmic \& Vision Research. 2011;6(1):50-53.

6. Pereira VM, Vargas MI, Marcos A, et al. Diagnostic neuroradiology for the interventional neuroradiologist. World Journal of Radiology. 2013;5(11):386-397.

7. Hamby WB: Carotid cavernous fistulae Springfield.III, Charles C Thomas, 1966

8. Harris FS, Rhoton AL. Anatomy of the cavernous sinus. A microsurgical study. JNeurosurg. 1976 Aug;45(2):169-80.

9. Hoogendijk CF, Pretorius E. Cavernous sinus anatomy as a basis for interpretation of the clinical picture and radiological investigations in a case of Entomophthorales infection. Clin Anat. 2006 Sep;19(6):535-9.

10. Bakan AA, Alkan A, Kurtcan S, Aralaşmak A, Tokdemir S, Mehdi E, Özdemir H.Cavernous Sinus: A Comprehensive Review of its Anatomy, Pathologic Conditions,and Imaging Features. Clin Neuroradiol. 2015 Jun;25(2):109-25
11. Théaudin M, Saint-Maurice J, Chapot R, et al. Diagnosis and treatment of dural carotid-cavernous fistulas: a consecutive series of 27 patients. Journal of Neurology, Neurosurgery, and Psychiatry. 2007;78(2):174-179.

12. Fattahi TT, Brandt MT, Jenkins WS, Steinberg B. Traumatic carotid-cavernous fistula: pathophysiology and treatment. J Craniofac Surg. 2003 Mar;14(2):240-6.

13. Kai Y, Morioka M, Yano S, et al. External Manual Carotid Compression is Effective in Patients with Cavernous Sinus Dural Arteriovenous Fistulae. Interventional Neuroradiology. 2007;13(Suppl 1):115122.

14. Korkmazer B, Kocak B, Tureci E, Islak C, Kocer N, Kizilkilic O. Endovascular treatment of carotid cavernous sinus fistula: A systematic review. World Journal of Radiology. 2013;5(4):143-155.

15. Baharvahdat H, Shabestari MM, Zabihyan S, Etemadresaei H, Blanc R, Piotin M. Transvenous Embolization of a Carotid Cavernous Fistula Complicated by a Hematoma at the Tentorial Edge. Interventional Neuroradiology. 2014;20(3):301-303.

16. Halbach VV, Higashida RT, Hieshima GB, Hardin CW, Pribram H. Transvenous embolization of dural fistulas involving the cavernous sinus. AJNR Am J Neuroradiol 1989; 10:377-383.

17. Charbel Mounayer, Michel Piotin, Laurent Spelle and Jacques Moret, Superior Petrosal Sinus Catheterization for Transvenous Embolization of a Dural Carotid Cavernous Sinus Fistula American Journal of Neitroradiology 2002; 23:1153-1155.

18. Uflacker R, Lima S, Ribas GC, Piske RL. Carotid-cavernous fistulas: Embolization through the superior ophthalmic vein approach. Radiology 1986: 159:175-179. 
19. Pansara A, Milburn JM, Perry M, Eubanks B. Clinical Images - A Quarterly Column: Transorbital Coil Embolization of a Carotid Cavernous Fistula. The Ochsner Journal. 2013;13(3):295-297.

20. Huded V. Endovascular balloon-assisted glue embolization of intranidal high flow fistula in brain AVM. Journal of Neurosciences in Rural Practice. 2013;4(Suppl 1):S148-S149.

21. Barrow DL, Fleischer AS, Hoffman JC. Complications of detachable balloon catheter technique in the treatment of traumatic intracranial arteriovenous fistulas. J Neurosurg 1982; 56:396-403.

22. Chaudhry IA, Elkhamry SM, Al-Rashed W, Bosley TM. Carotid Cavernous Fistula: Ophthalmological Implications. Middle East African Journal of Ophthalmology. 2009;16(2):57-63.

23. Saraf R, Shrivastava M, Kumar N, Limaye U. Embolization of cranial dural arteriovenous fistulae with ONYX: Indications, techniques, and outcomes. The Indian Journal of Radiology \& Imaging. 2010;20(1):26-33.

24. Lamirel C, Newman NJ, Biousse V. Vascular Neuro-ophthalmology. Handbook of clinical neurology / edited by PJ Vinken and GW Bruyn. 2009;93:595-611.

25. Tatewaki Y, Nishimura S, Ezura M, et al. Endovascular GDC Treatment of an Idiopathic Carotid-Cavernous Fistula Caused by Aneurysmal Rupture of the Intra-Cavernous Carotid Artery: Case Report. Interventional Neuroradiology. 2006;12(Suppl 1):174-177. 